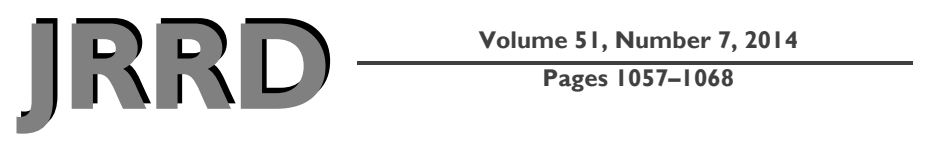

\title{
Changes in cognition and continence as predictors of rehabilitation outcomes in individuals with severe traumatic brain injury
}

\author{
David S. Kushner, MD; ${ }^{*}$ Doug Johnson-Greene, PhD \\ Department of Physical Medicine and Rehabilitation, University of Miami Miller School of Medicine, Miami, FL
}

\begin{abstract}
The study objective was to examine postacute changes in bowel and bladder continence and cognition after severe traumatic brain injury (TBI) in persons with long-term functional recovery to full independence. This case series included nine patients initially admitted to inpatient rehabilitation (IR) with severe TBI who had returned to prior responsibilities and functional independence by 8 to 15 mo. Patients had initial Glasgow Coma Scale scores of 3 to 6 , posttraumatic amnesia durations of 18 to $70 \mathrm{~d}$, time-to-follow-commands of 16 to $56 \mathrm{~d}$, initial abnormal brain computed tomography scans, and initial pupil abnormalities. IR Functional Independence Measure (FIM) cognitive and sphincter score improvements were compared with national TBI FIM data from Uniform Data Systems for Medical Rehabilitation (UDSMR) for 2010 ( $n=16,368)$. All patients had IR improvements in cognitive and sphincter FIM scores approximately twice the national UDSMR data for 2010. All patients had combined IR discharge sphincter FIM scores that were 12 or greater, indicating independence to modified independence with bowel and bladder function with no incontinence. Five participants (55\%) were admitted to IR with sphincter FIM scores of 11 to 12, indicating recovery of continence during acute care. These findings suggest potential usefulness of IR cognitive FIM score changes and of the recovery of bowel and bladder continence for predicting favorable functional outcomes following severe TBI.
\end{abstract}

Key words: fecal incontinence, Functional Independence Measure score, outcomes assessment, postacute change, prediction, prognosis, rehabilitation, TBI, traumatic brain injury, urinary incontinence.

\section{INTRODUCTION}

Traumatic brain injury (TBI) is an important public health concern due to its magnitude, costs, and clinical and social consequences in both military and civilian populations. Rates of TBI increased in every Active Duty service branch from 2000 through 2011, with the largest increases occurring among Active Duty Army and Marine Corps servicemembers nationally and in global theaters of operation [1]. The prevalence of TBI in veterans returning from the conflicts in Iraq and Afghanistan is significant. For example, 59,218 veterans of these conflicts were evaluated or treated at a Department of Veterans Affairs medical center from October 1, 2001, to

Abbreviations: CRASH $=$ Corticosteroid Randomization After Significant Head Injury (database), CT $=$ computed tomography, FIM = Functional Independence Measure, GCS = Glasgow Coma Scale, IMPACT = International Mission on Prognosis and Analysis of Clinical Trials in TBI (database), IR = inpatient rehabilitation, $\mathrm{NPH}=$ normal pressure hydrocephalus, PTA $=$ posttraumatic amnesia, PTSD $=$ posttraumatic stress disorder, STBI = severe traumatic brain injury, TBI = traumatic brain injury, TFC = time-to-follow-commands, UDSMR $=$ Uniform Data Systems for Medical Rehabilitation. *Address all correspondence to David S. Kushner MD; Department of Physical Medicine and Rehabilitation, University of Miami Miller School of Medicine, 20601 Old Cutler Rd, Miami, FL 33189; 305-259-6418; fax: 305-251-5978. Email: dkushner@med.miami.edu

http://dx.doi.org/10.1682/JRRD.2014.01.0002 
December 31, 2011, for a condition related to a TBI [1-2]. Also, between January 2003 and December 2011, 1,255 veterans experienced moderate TBI to severe TBI (STBI) in the Iraq and Afghanistan conflicts [3]. The National Center for Injury Prevention and Control estimates that each year approximately 1.7 million civilians in the United States sustain a TBI, of which about 1.36 million are treated and released from emergency departments, while many of the 275,000 that are hospitalized have moderate TBI to STBI [2]. Uncertainty regarding longterm outcome expectations is a source of significant anguish to the families of veterans and civilians with recent STBIs. Identification of specific predictors of long-term rehabilitation outcomes for veteran and civilian patients having an STBI would have uses that would include family counselling.

Long-term neurologic and cognitive deficits that impede the return to independent living are expected in most individuals experiencing an STBI; however, some of these patients recover full independence, which includes a successful return to work, school, and prior responsibilities. A consensus conference sponsored by the National Institutes of Health in 1999 determined that further research was necessary to identify specific factors affecting long-term functional outcomes in people with TBI [4]. Identification of factors predictive of improvement could have important implications for intervention development, cost projection, allocation of funding for TBI treatment, and family counselling.

Studies published since 1999 have reported impractical or conflicting results regarding individual acute and postacute care factors that may be predictive of functional outcomes after moderate TBI to STBI in both civilians and veterans. For example, late and/or chronic postacute quantitative volumetric changes in brain parenchyma and cerebrospinal fluid spaces on computed tomography $(\mathrm{CT})$ scan images at 12 to $14 \mathrm{yr}$ post-TBI in a group of Vietnam veterans having closed or penetrating head trauma were correlated with the potential for a return to gainful employment and passing scores on the Armed Forces Qualification Test and a disability scale that combined various clinical and neuropsychological components [5-6]. However, the practical utility of these findings may be limited by the prolonged time interval from the acute TBI. Also, multiple acute TBI characteristics are now being used in two research models, the Corticosteroid Randomization after Significant Head Injury (CRASH) and International Mission on Prognosis and Analysis of Clinical Trials in TBI (IMPACT) databases, both of which have been validated as useful instruments for the determination of early prognosis, including outcomes at 6 mo [7-8]; however, the predictive value of these two models beyond 6 mo remains uncertain.

The literature examining the use of early postacute measures for predicting long-term functional outcomes beyond 6 mo has not been fully explored, and cases of long-term recovery to full independence have been the focus of limited research in both civilians and veterans. The measures that are most commonly used during inpatient rehabilitation (IR) and outpatient rehabilitation to quantify rather than predict outcomes include the Glasgow Outcome Scale, the Extended Glasgow Outcome Scale, the Disability Rating Scale, the Functional Assessment Measure, the Functional Status Examination, various TBI-specific and generic quality of life measures, various neuropsychological testing batteries, and the Functional Independence Measure (FIM) [9-13].

The FIM is administered nationally to many IR patients, including those with TBI, which would make it a practical tool for predicting long-term functional outcomes. A number of studies have looked at the utility of the FIM for long-term outcome prediction [14-16]. However, these studies have relied primarily on total FIM scores, which include both the motor and cognitive components of this scale, on admission and/or on discharge from IR [14-16]. One potential problem with including the FIM motor score for outcome prediction is the inability to separate the effects of physical trauma from TBIrelated disability in the motor score components. However, cognitive and sphincter FIM scores, which measure the return of bowel and bladder continence, may be more directly related to TBI. Sphincter incontinence is common after an acute TBI, and its persistence may be associated with poorer functional outcomes [17-18]. This case series examines cognitive and sphincter FIM score gains and the return of bowel and bladder continence by discharge from IR in nine civilian patients having an STBI who had favorable long-term recovery with a return to full functional independence by 8 to 15 mo postinjury.

\section{METHODS}

\section{Patients}

Nine civilian patients with STBI, treated by the first author of this study, were selected for inclusion in this case series because of their full functional recoveries and return to prior responsibilities and professional roles 
within the community. We sought to retrospectively examine improvement in bowel and bladder continence and cognitive FIM scores in this case series. The patients were admitted to IR at 16 to $37 \mathrm{~d}$ after acute nonpenetrating TBI. The nine patients had initial Glasgow Coma Scale (GCS) scores of 3 to 6, abnormal initial brain CT scans consistent with diffuse axonal injury, and initial pupil abnormalities. Patients had posttraumatic amnesia (PTA) durations of 18 to $70 \mathrm{~d}$ and time-to-follow-commands (TFC) of 16 to $56 \mathrm{~d}$. IR ranged from 18 to $73 \mathrm{~d}$. Outpatient rehabilitation ranged from 3 to 9 mo. Following outpatient rehabilitation, all patients resumed functional independence, including the return of independent living, gainful employment, and/or school. Two of the patients subsequently graduated from college; one became a practicing physician and the other a practicing attorney. Table 1 summarizes the clinical histories for these patients.

\section{Procedure}

Participant FIM scores were measured at the time of admission and on discharge to IR to assess progress in motor, cognitive, and bowel and bladder sphincter continence status. Table 2 summarizes IR participant FIM scores. Participant IR cognitive and sphincter FIM score improvements were compared with national normative TBI FIM data from Uniform Data Systems for Medical Rehabilitation (UDSMR) for $2010(n=16,368)$. Table 3 summarizes UDSMR national normative FIM score data for STBI from 2010.

Many U.S. national accredited IR programs report the initial and discharge FIM data to UDSMR, a company that maintains all the annual pooled data for any patient coded as a TBI during IR. Thus, the FIM score data used for reference comparison in this study may have included moderate and mild TBI data in addition to STBI scores. Z-scores were calculated by subtracting the UDSMR mean score from the case series average and dividing by the UDSMR standard deviation.

\section{RESULTS}

All participants returned to functional independence by 8 to 15 mo following acute STBI, including their ability to return to prior responsibilities such as work, school, homemaking, driving, and the ability to live independently; four are currently employed in professional roles (physician, accountant, lawyer, and bank manager) at 3 to 14 yr postinjury.

Average initial and discharge cognitive FIM scores were 13.2 and 26.8, respectively. IR cognitive FIM scores improved an average of 13.6 points compared with $6.0 \pm 5.8$ (mean \pm standard deviation) for UDSMR, a Zscore improvement of 1.31. Average initial and discharge sphincter FIM scores were 7.8 and 13.4, respectively. Sphincter (bowel and bladder) FIM scores improved an average of 5.7 points compared with $3.0 \pm 3.7$ for UDSMR, a Z-score improvement of 0.71.There was a ceiling effect on the possible sphincter FIM score improvements since five participants were admitted to IR with combined sphincter FIM scores of 11 to 12, indicating significant recovery of continence during acute care. Table 2 summarizes IR patient FIM scores. Table 3 summarizes UDSMR national normative FIM score data for STBI from 2010.

Participants had IR improvements in cognitive FIM scores more than twice the national UDSMR average for 2010, and approximately two times the improvement in sphincter FIM scores for that year even with the ceiling effect described previously. Also, bowel and bladder continence improved during IR for each case participant, and all had combined bowel and bladder FIM scores of 12 or greater, indicating independence to modified independence with bowel and bladder function with no incontinence. The average combined discharge sphincter FIM score for participants was 13.4 compared with $9.8 \pm 3.8$ for the national UDSMR scores.

\section{DISCUSSION}

All participants met the criteria for STBI but resumed major life roles, including the return to work and school and the ability to function independently, within 8 to $15 \mathrm{mo}$ of the trauma; several subsequently achieved professional degrees and/or assumed professional roles. These favorable functional outcomes are atypical given the usual acute care physical and behavioral TBI prognostic indicators for these participants, such as the GCS scores, PTA durations, TFC, initial brain CT scan findings, and initial pupil abnormalities.

The nine patients had initial emergency department GCS scores of 3 to 6 . The GCS score is the clinical measure most commonly used in the determination of initial TBI severity [19-20]. GCS scores have been shown to 
JRRD, Volume 51, Number 7, 2014

Table 1.

Clinical histories.

\begin{tabular}{|c|c|c|c|c|c|c|c|c|c|}
\hline Variable & Case 1 & Case 2 & Case 3 & Case 4 & Case 5 & Case 6 & Case 7 & $\begin{array}{l}\text { Case } 8 \\
\end{array}$ & Case 9 \\
\hline \multirow[t]{2}{*}{$\overline{\text { Age (yr) }}$} & 21 & 19 & 26 & 27 & 24 & 45 & 16 & 34 & 16 \\
\hline & $\mathrm{F}$ & $\mathrm{F}$ & M & M & M & M & M & M & M \\
\hline \multicolumn{10}{|l|}{ Initial GCS Score } \\
\hline \multirow[t]{2}{*}{$\mathrm{ED}$} & 4 & 3 & 6 & 3 & 4 & 3 & 3 & 3 & 3 \\
\hline & $\begin{array}{l}\text { Dilated } \\
\text { nonreactive }\end{array}$ & Reactive & $\begin{array}{l}\text { Sluggish } \\
\text { bilateral }\end{array}$ & $\begin{array}{l}\text { Sluggish } \\
\text { bilateral }\end{array}$ & $\begin{array}{l}\text { Sluggish } \\
\text { bilateral }\end{array}$ & Sluggish & $\begin{array}{l}\text { Sluggish } \\
\text { bilateral }\end{array}$ & $\begin{array}{l}3 \mathrm{~mm} \text { reactive } \\
\text { bilateral }\end{array}$ & $\begin{array}{l}\text { Reactive } \\
\text { bilateral }\end{array}$ \\
\hline \multirow[t]{2}{*}{$\begin{array}{l}\text { Initial Brain CT } \\
\text { Scan }\end{array}$} & $\begin{array}{l}\text { SDH, SAH, } \\
\text { edema, sub- } \\
\text { falcine } \\
\text { herniation }\end{array}$ & $\begin{array}{l}\text { Contusions, } \\
\text { edema }\end{array}$ & $\begin{array}{l}\text { Bifrontal hem- } \\
\text { orrhagic con- } \\
\text { tusions, } \\
\text { SAH, DAI }\end{array}$ & $\begin{array}{l}\text { DAI, cerebral } \\
\text { edema }\end{array}$ & $\begin{array}{l}\text { Frontal tempo- } \\
\text { ral hemor- } \\
\text { rhagic } \\
\text { contusions } \\
\text { (R), SAH, } \\
\text { DAI }\end{array}$ & $\begin{array}{l}\text { Temporal frac- } \\
\text { ture (L), } \\
\text { SDH (L), } \\
\text { bihemisphere } \\
\text { contusions }\end{array}$ & $\begin{array}{l}\text { Basal ganglia } \\
\text { hematoma } \\
\text { with mass } \\
\text { effect (L) }\end{array}$ & $\begin{array}{l}\text { Bifrontal- } \\
\text { parietal } \\
\text { contusions, } \\
\text { SDH with } \\
\text { mass effect } \\
\text { (L), midline } \\
\text { shift }\end{array}$ & $\begin{array}{l}\text { Bihemisphere } \\
\text { hemorrhagic } \\
\text { and brain stem } \\
\text { contusions, } \\
\text { SAH, DAI, } \\
\text { edema }\end{array}$ \\
\hline & $\begin{array}{l}\text { Decerebrate } \\
\text { rigidity }\end{array}$ & $\begin{array}{l}\text { Intubated, } \\
\text { coma }\end{array}$ & $\begin{array}{l}\text { Confused, } \\
\text { obtunded } \\
\text { nonfocal } \\
\text { examination }\end{array}$ & $\begin{array}{l}\text { Unresponsive, } \\
\text { comatose }\end{array}$ & $\begin{array}{l}\text { Unresponsive, } \\
\text { comatose }\end{array}$ & $\begin{array}{l}\text { Comatose, } \\
\text { facial frac- } \\
\text { tures, multi- } \\
\text { ple trauma }\end{array}$ & $\begin{array}{l}\text { Comatose, } \\
\text { cephalo- } \\
\text { hematoma } \\
\text { (L) }\end{array}$ & $\begin{array}{l}\text { Comatose, } \\
\text { seizures, } \\
\text { bilateral } \\
\text { pneumothorax }\end{array}$ & $\begin{array}{l}\text { Comatose, C6 } \\
\text { spine fracture, } \\
\text { frontal scalp } \\
x \text { laceration }\end{array}$ \\
\hline \multirow[t]{2}{*}{ Intervention } & $\begin{array}{l}\text { Holocraniec- } \\
\text { tomy }\end{array}$ & $\begin{array}{l}\text { Ventriculos- } \\
\text { tomy } \\
\text { ventilation }\end{array}$ & $\begin{array}{l}\text { Supportive } \\
\text { care }\end{array}$ & $\begin{array}{l}\text { Supportive } \\
\text { care }\end{array}$ & $\begin{array}{l}\text { Ventriculos- } \\
\text { tomy } \\
\text { ventilation }\end{array}$ & $\begin{array}{c}\text { Ventilation, } \\
\text { mannitol }\end{array}$ & $\begin{array}{c}\text { Ventilation } \\
\text { mannitol } \\
\text { osmotic }\end{array}$ & $\begin{array}{l}\text { Craniotomy } \\
\text { (L), } \\
\text { ventilation }\end{array}$ & $\begin{array}{l}\text { Ventriculostomy, } \\
\text { ventilation }\end{array}$ \\
\hline & Pneumonia & $\begin{array}{l}\text { Severe hypo- } \\
\text { natremia }\end{array}$ & $\begin{array}{l}\text { Respiratory } \\
\text { failure, } \\
\text { pneumonia }\end{array}$ & $\begin{array}{l}\text { Respiratory } \\
\text { failure }\end{array}$ & $\begin{array}{l}\text { Respiratory } \\
\text { failure, } \\
\text { pneumonia }\end{array}$ & $\begin{array}{l}\text { Respiratory } \\
\text { failure }\end{array}$ & $\begin{array}{l}\text { Respiratory } \\
\text { failure, vocal } \\
\text { cord } \\
\text { paralysis }\end{array}$ & $\begin{array}{l}\text { Respiratory } \\
\text { failure }(7 \mathrm{~d})\end{array}$ & $\begin{array}{l}\text { Respiratory } \\
\text { failure }\end{array}$ \\
\hline $\mathrm{TFC}(\mathrm{d})$ & 30 & 16 & 35 & 56 & 31 & 25 & 20 & 22 & 30 \\
\hline \multirow[t]{2}{*}{$\begin{array}{l}\text { Current Employ- } \\
\text { ment Status (time } \\
\text { postinjury) }\end{array}$} & $\begin{array}{l}\text { Physician } \\
(9 \mathrm{yr})\end{array}$ & $\begin{array}{l}\text { Lawyer } \\
(14 \mathrm{yr})\end{array}$ & $\begin{array}{r}\text { Banker } \\
(3 \mathrm{yr})\end{array}$ & $\begin{array}{l}\text { Hospital } \\
\text { orderly (2 yr, } \\
8 \mathrm{mo})\end{array}$ & $\begin{array}{l}\text { College } \\
\text { student } \\
(23 \mathrm{mo})\end{array}$ & $\begin{array}{l}\text { Shift manager } \\
\quad(10 \mathrm{mo})\end{array}$ & $\begin{array}{l}\text { Student, 10th } \\
\text { grade }(-)\end{array}$ & $\begin{array}{l}\text { Payroll } \\
\text { manager } \\
(12 \mathrm{mo})\end{array}$ & $\begin{array}{l}\text { Student, 10th } \\
\text { grade (11 mo) }\end{array}$ \\
\hline & Normal & $\begin{array}{l}\text { 3rd nerve } \\
\text { palsy, mild } \\
\text { hemiparesis, } \\
\text { dysarthria }\end{array}$ & $\begin{array}{l}\text { Wide-based } \\
\text { gait, poor } \\
\text { tandem gait }\end{array}$ & $\begin{array}{l}\text { Mild spastic- } \\
\text { ity, weak- } \\
\text { ness (R UL) }\end{array}$ & $\begin{array}{l}\text { Partial foot } \\
\text { drop (R), } \\
\text { unable to run }\end{array}$ & $\begin{array}{l}\text { Eye blindness } \\
\text { (R), 3rd } \\
\text { nerve palsy } \\
\text { (R), dysar- } \\
\text { thria, mild } \\
\text { imbalance }\end{array}$ & $\begin{array}{l}\text { Residual hemi- } \\
\text { paresis (R) }\end{array}$ & $\begin{array}{l}1 \text { seizure since } \\
\text { discharge, } \\
\text { difficulty } \\
\text { with tandem } \\
\text { gait }\end{array}$ & $\begin{array}{l}\text { Mild dysarthria, } \\
\text { mild } \\
\text { hemiparesis } \\
\text { (L) }\end{array}$ \\
\hline
\end{tabular}

$\mathrm{C}=$ cervical, $\mathrm{CT}=$ computed tomography, $\mathrm{DAI}=$ diffuse axonal injury, $\mathrm{ED}=$ emergency department, $\mathrm{F}=$ female, GCS $=$ Glasgow Coma Scale, $\mathrm{IR}=$ inpatient rehabilitation, $\mathrm{L}=$ left, $\mathrm{M}=$ male, $\mathrm{PTA}=$ posttraumatic amnesia, $\mathrm{R}=$ right, $\mathrm{SAH}=$ subarachnoid hemorrhage, $\mathrm{SDH}=$ subdural hemorrhage, $\mathrm{TFC}=$ time-to-followcommand, UL $=$ upper limb. 
Table 2.

Inpatient rehabilitation Functional Independence Measure (FIM) scores.

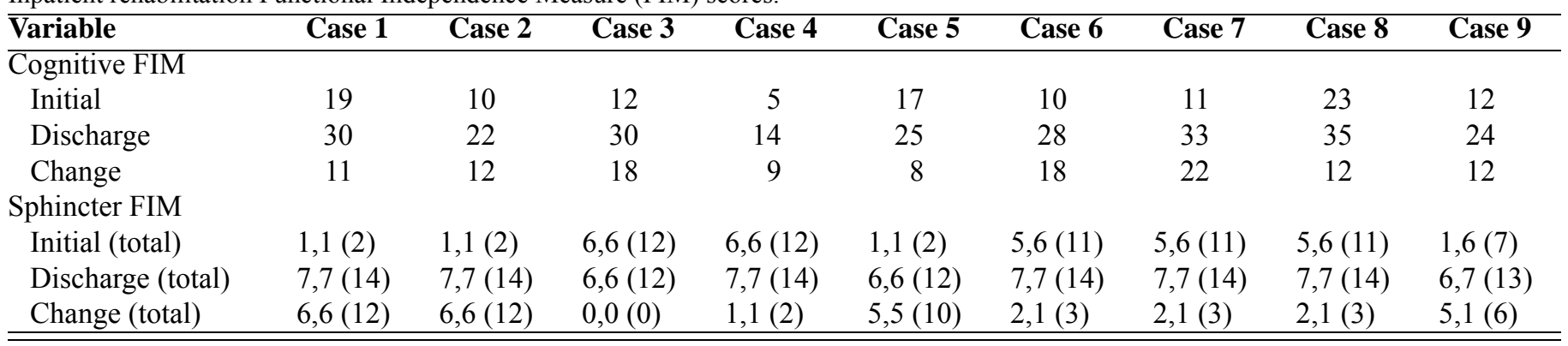

Table 3.

2010 National Uniform Data System for Medical Rehabilitation (UDSMR) inpatient rehabilitation traumatic brain injury final and corrected Function Independence Measure (FIM) scores $(N=16,368)$.

\begin{tabular}{lr}
\hline FIM Scores & Mean \pm Standard Deviation \\
\hline Cognitive FIM & $16.97 \pm 7.74$ \\
Initial & $22.95 \pm 7.43$ \\
Discharge & $5.99 \pm 5.79$ \\
Change & \\
Sphincter FIM & $6.84 \pm 3.92$ \\
Initial & $9.85 \pm 3.85$ \\
Discharge & $3.01 \pm 3.73$ \\
Change & Note: Permission for data use and source of this data is UDSMR. \\
\hline \hline
\end{tabular}

correlate well with IR admission cognitive FIM scores [21] but alone are of limited use for predicting long-term functional outcomes [19,21-23]. Also, the initial GCS scores may be compromised by sedation, intubation, intoxication, and eye swelling [21-23]. Case participants had PTA duration of 18 to $70 \mathrm{~d}$. PTA duration is another indicator of TBI severity that has been used to predict long-term functional outcomes [19,21,24-26]. Generally, school- to working-age people with TBI having PTA durations of less than $14 \mathrm{~d}$ have more favorable functional outcomes at $1 \mathrm{yr}$ in terms of the return to full- or part-time employment, school, or homemaking, whereas those with PTA durations of more than $28 \mathrm{~d}$ have poorer outcomes. An investigation of veterans and military dependents having moderate to severe nonpenetrating TBI found that the accuracy of PTA in outcome prediction was improved when persistent clinical neurologic impairments such as limb paresis, imbalance, and problems with gait were present [27]. However, in this case series, eight of the nine patients had residual neurologic impairments that included limb paresis, imbalance, and problems with gait, which did not improve the predictive value of their PTA durations (18-70 d) since all had favorable outcomes that would not have been expected. Participants had TFC of 16 to $56 \mathrm{~d}$. TFC has been shown to correlate with long-term functional outcomes in TBI [23-24,28], with poorer outcomes expected in cases having TFC greater than 1 to $2 \mathrm{wk}$ [21-22], particularly when the prolonged TFC is associated with pathology on brain imaging studies [28]. All nine participants in this case series had favorable outcomes despite their prolonged TFC (16-56 d) and abnormal neuroimaging.

All participants had intracranial pathology on admission neuroimaging during acute care associated with poor outcomes such as contusions, epidural and subdural hemorrhage, intracerebral hematoma, depressed skull fracture, midline shift, and diffuse axonal injury [22,28-29]. Contusions involving the temporal lobes and the brain stem may be associated with the worst outcomes, and these findings were present in several participants [22]. Cases having diffuse axonal TBI with initial pupil abnormalities are also expected to have poor outcomes at 3 to $5 \mathrm{yr}$ [28]. All but one participant had initial abnormal pupil reactivity documented. Initial pupil abnormalities have been generally regarded as a poor short- and long-term prognostic sign when associated with acute intracranial pathology in TBI $[19,22,29]$.

This STBI case series raises important questions about which preinjury and/or postinjury case characteristics or indicators would be sensitive enough to predict the potential for the return to independent living and gainful employment after STBI. Young age, preinjury productivity, college education, prior professional or managerial occupation, discharge from IR to home, duration of rehabilitation, good social and/or professional support network, absence of psychiatric symptoms, and improvement from admission to discharge IR FIM scores are all factors associated with a greater potential for postinjury gainful employment [16,30-33]. Sex seems to have no significant 
influence on outcomes after TBI [34]. Early interventions following acute injury to reduce intracranial hypertension and mass effect have been shown to improve outcomes [35-36]. Initial treatment of STBI at a level 1 trauma center may be associated with a greater return of functional independence [37]. Continuous early rehabilitation interventions beginning during acute care and spanning IR and outpatient rehabilitation have been shown to improve outcomes after TBI [38-41]. Also, an investigation of veterans having nonpenetrating moderate TBI to STBI found that those with a latency of less than $48 \mathrm{~d}$ in trauma acute care prior to transfer to postacute IR were 2.4 times more likely to be productive in terms of ability to return to work at $1 \mathrm{yr}$ [42]. The nine patients in this case series shared most of these characteristics associated with good outcomes, including early interventions following acute injury to reduce intracranial hypertension and mass effect at a level 1 trauma center, latency of less than $48 \mathrm{~d}$ for transfer from acute care to postacute IR, discharge from IR to home with family, outpatient rehabilitation, excellent social support, and no psychiatric symptoms following recovery from PTA. An additional indicator common to the nine patients was improvement from admission to discharge in IR cognitive FIM scores of 8 to 22 points, with an average improvement in IR cognitive FIM scores more than twice that of the national UDSMR pooled data for 2010 .

In this case series, it is also noteworthy that five of the participants demonstrated an improvement in sphincter continence from supervision to modified independence during acute care based on their admission IR sphincter FIM scores. Also, all nine had combined bowel and bladder FIM scores of 12 or greater, indicating independence to modified independence with bowel and bladder function with no incontinence by discharge from IR. Sphincter incontinence is commonly associated with diseases that involve cognitive impairment and loss of functional independence such as untreated normal pressure hydrocephalus (NPH), various dementias, stroke, and acute TBI [17,18,42-46]. Persistence of sphincter incontinence in patients with TBI is associated with poor functional outcomes [17-18]. Data from this case series seems to suggest that the recovery of continence after TBI may be associated with favorable functional outcomes. Similarly, patients having NPH that are successfully treated with shunting have recovery of continence and cognition [46]. Brain mapping studies suggest that the prefrontal cortex has important projections to other brain regions in the regulation of continence [47]. The prefrontal cortex is also known to have important connections with other brain regions in the integration of cognition. Thus, it would seem plausible that the recovery of continence could parallel the recovery of cognition due to the commonality of the pathways originating in the prefrontal cortex.

Another question raised by this civilian case series would be whether or not the findings, regarding improvements in cognition and sphincter control as potential predictors of rehabilitation outcomes, would also be applicable for veterans with STBI. Veterans having STBI from military conflicts may have clinical characteristics that compare and differ from those of the civilians in this case series in several important ways. This case series involved a civilian group of mostly young patients, ages 16 to $45 \mathrm{yr}$, having STBI with closed-head trauma as a result of high-speed motor vehicle accidents. Veterans having TBI are also mostly young; however, in contrast, they have a higher incidence of penetrating head trauma from blasts and gunshot wounds than closed-head TBI, which may also occur from motor vehicle crashes or other nonpenetrating mechanisms [3]. Reportedly, from 2004 to 2008, the ratio of moderate TBI to STBI as the result of penetrating versus closed-head trauma in Iraq and Afghanistan was $>2: 1$; however, the ratio changed to 1.3:1 in 2008 to 2010 , possibly due to improvements in the use of protective measures and tactics and/or progress in diagnosis of closed-head TBIs [3]. Reportedly, veterans with TBI are significantly more likely to undergo intracranial pressure monitoring and operative neurosurgical intervention than civilians [48], which may improve outcomes [35-36]. However, in this case series, all participants had intracranial pressure monitoring and two underwent neurosurgical procedures that included a craniectomy and a craniotomy.

In civilian populations with TBI, most STBIs tend to occur from traffic-related accidents compared with falls and violence, but interestingly, the functional recovery may be best in the civilian patients having traffic accidents as a cause of trauma [49-50]. Reasoning for poorer outcomes in patients having TBI due to violence remains uncertain [49-50] but has been attributed to posttraumatic stress disorder (PTSD) [51]. PTSD may be more likely to occur in veterans sustaining significant injury in intense and/or violent combat situations that may include blast neurotrauma [51-53]. PTSD may also coexist with depression and/or chronic pain [52,54], but it may also 
occur independently of these psychological comorbidities [54]. None of the patients in this case series had PTSD, depression, or chronic pain. Chronic pain, anxiety, and depression can act as distractors of concentration and attention that may interfere with recovery in mild TBI [55]. However, in all classifications of TBI severity, including STBI, these psychological comorbidities and PTSD may also be related to lesions involving the prefrontal lobes and/or other regions of the brain having prefrontal connections [52,56-60]. As described previously, prefrontal connections may also be important in cognition and sphincter continence. Thus, it seems plausible that the recovery of continence and/or cognition during IR may still have potential as markers of future recovery of functional independence in veterans having psychological comorbidities in association with STBI as a result of combat-related trauma, including blast neurotrauma, which was not a mechanism of injury represented in this case series.

The favorable long-term recoveries to full independence in this case series would not have been expected based on the usual acute prognostic indicators reviewed in this article. The case participants had an average improvement in IR cognitive FIM scores more than twice that of the national UDSMR pooled data for 2010 and approximately twice the improvement seen in the national sphincter FIM scores for that year, even with the previously described ceiling effect, since recovery of bowel and bladder continence started in five of the patients during the acute care hospitalization. This case series suggests the potential usefulness of IR cognitive and sphincter FIM improvements and particularly of the return of bowel and bladder continence by IR discharge for predicting favorable remote functional outcomes in STBI. Further research is necessary to investigate whether bowel and bladder continence status is indeed a useful tool in STBI outcome prediction alone and/or in combination with other measures or factors such as those used in the IMPACT [7-8] and CRASH [8] databases. Similarly, further research is needed to determine whether a ratio of IR cognitive FIM score improvements of approximately twice the annual UDSMR average may also be useful in STBI outcome prediction either alone and/or in combination with any of the other measures or factors discussed in this article, including bowel and bladder continence status.

\section{LIMITATIONS}

Foremost, this is a small case series rather than a randomized study and thus subject to the many limitations of this type of observational design. Patients were included in this case series based on the first author's knowledge of the favorable outcome and also contingent on the availability of the medical record for review with consent. If records were not available for evaluation regarding data necessary for this case series investigation, then a patient having a known favorable outcome would not have been included. Furthermore, this was a civilian case series involving STBI from nonpenetrating trauma; thus, limitations may exist in applying the findings to veterans with penetrating STBI.

Also, it is important to note that the national UDSMR data used for comparison in this study includes all IR persons with TBI, which would include those with moderate TBI and perhaps some with mild TBI. The UDSMR data set is thus more diverse than that of the STBI case series in this report. Therefore, the average change in cognitive and sphincter FIM scores in the UDSMR sample may be restricted by a ceiling effect inherent with this data set. It is also noteworthy that there definitely was a ceiling effect on the possible sphincter FIM score improvements in this case series since five participants were admitted to IR with combined sphincter FIM scores of 11 to 12, indicating significant recovery of continence during acute care.

In addition, the comparisons with national normative UDSMR FIM data were not true statistical comparisons when taking into account the standard deviations of the FIM scores in the reference sample. Despite these limitations, the $Z$-score calculated for the FIM cognitive change was greater than $Z=1.0$ though not greater than $Z=1.96$ at the 0.5 level of significance, suggesting the need for a large sample study. A further limitation in this small case series would be that the conclusions could be subject to low base rate phenomena since a favorable functional outcome after a STBI is uncommon. Positive and negative predictive information that would be needed in further research to counter the problem of the low base rate phenomena would be data regarding the number of individuals having strong IR cognitive and sphincter FIM scores who do not go on to have favorable functional recoveries and/or the number of individuals having unimpressive IR cognitive and sphincter FIM scores who go on to have full functional recoveries to complete independence. Also, it is possible that the cognitive FIM score changes 
in this case series may only demonstrate that patients with STBI with favorable functional recoveries will have greater gains during IR, which would be expected. However, the return of bowel and bladder continence by discharge from IR in these patients with STBI having subsequent long-term full functional recoveries to complete independence was unexpected. This finding suggests the possibility that sphincter continence may be a novel marker that may be useful in STBI outcome prediction.

\section{CONCLUSIONS}

In this retrospective case series investigation, the data seem to suggest that a return of bowel and bladder continence during acute and/or early postacute care and a cognitive recovery with cognitive FIM gains of nearly twice the national average during IR may be associated with favorable long-term functional outcomes following STBI. Conversely, persistence of incontinence may be associated with poor outcomes in TBI [15-16]. If return of bowel and/or bladder continence and cognition is shown in subsequent prospective studies to be useful in long-term STBI outcome prediction, possible applications might include early determination of rehabilitation services targeted to specific functional deficits, vocational rehabilitation planning, intervention development, resource allocation, cost projection, and family counseling.

A key finding of interest in this study was the association of the recoveries with a return of bowel and bladder continence, which occurred in 55 percent of these cases during acute care. The predictive value of bowel and bladder continence in long-term recovery following STBI should be further investigated in a large sample study because this may be an often overlooked but important factor associated with the potential for a favorable long-term outcome to full independence. Perhaps the association between STBI recovery and the return of bowel and bladder continence and cognition could be investigated further via the vast database of the VA national healthcare system in veterans having penetrating and nonpenetrating head trauma.

\section{ACKNOWLEDGMENTS}

\section{Author Contributions:}

Study concept and design: D. S. Kushner, D. Johnson-Greene.

Acquisition of data: D. S. Kushner.
Analysis and interpretation of data: D. Johnson-Greene.

Drafting of manuscript: D. S. Kushner.

Critical revision of manuscript for important intellectual content:

D. S. Kushner, D. Johnson-Greene.

Financial Disclosures: The authors have declared that no competing interests exist.

Funding/Support: This material was based on work supported by Department of Physical Medicine and Rehabilitation funding by the U.S. Department of Education, National Institute of Disability Research and Rehabilitation (grant H133A120099, a TBI Model Systems grant).

Additional Contributions: An earlier version of this abstract/study titled "Severe TBI outcome prediction: Usefulness of FIM scores during inpatient rehabilitation" was given at the American Academy of Neurology Annual Meeting in New Orleans, Louisiana, in April 2012. Institutional Review: Consent was obtained from all case participants and/or families for participation in this case series and for related longitudinal follow-up. Clinical research review committee approval was given by the host institution for this study.

Participant Follow-Up: The authors will inform the participants who are still in touch. Other participants have been encouraged to check with the first author for publication updates.

\section{REFERENCES}

1. Centers for Disease Control and Prevention, National Institutes of Health, Department of Defense, and Department of Veterans Affairs Leadership Panel. Report to Congress on traumatic brain injury in the United States: Understanding the public health problem among current and former military personnel [Internet]. Washington (DC): CDC, NIH, DOD, and VA; 2013 Jun. Available from:

http://www.cdc.gov/traumaticbraininjury/pdf/

Report to Congress on Traumatic Brain_Injury 2013a.pdf

2. Epidemiology Program, Post-Deployment Health Group, Office of Public Health, Veterans Health Administration, Department of Veterans Affairs. Analysis of VA health care utilization among Operation Enduring Freedom (OEF), Operation Iraqi Freedom (OIF), and Operation New Dawn (OND) veterans: Cumulative from 1st qtr FY 2002 through 1st qtr FY 2013 (October 1, 2001-December 31, 2012). Washington (DC): Department of Veterans Affairs; 2012 Mar. Available from: http://www.publichealth.va.gov/docs/ epidemiology/healthcare-utilization-report-fy2012-qtr1.pdf

3. Orman JA, Geyer D, Jones J, Schneider EB, Grafman J, Pugh MJ, Dubose J. Epidemiology of moderate-to-severe penetrating versus closed traumatic brain injury in the Iraq and Afghanistan wars. J Trauma Acute Care Surg. 2012; 73(6 Suppl 5):S496-502. [PMID:23192076] http://dx.doi.org/10.1097/TA.0b013e318275473c

4. NIH Consensus Development Panel on Rehabilitation of Persons With Traumatic Brain Injury. Consensus conference. 
Rehabilitation of persons with traumatic brain injury. JAMA. 1999;282(10):974-83. [PMID:10485684]

http://dx.doi.org/10.1001/jama.282.10.974

5. Reider-Groswasser II, Groswasser Z, Ommaya AK, Schwab K, Pridgen A, Brown HR, Cole R, Salazar AM. Quantitive imaging in late traumatic brain injury. Part I: Late imaging parameters in closed and penetrating head injuries. Brain Inj. 2002;16(6):517-25. [PMID:12119087] http://dx.doi.org/10.1080/02699050110119141

6. Groswasser Z, Reider-Groswasser II, Schwab K, Ommaya AK, Pridgen A, Brown HR, Cole R, Salazar AM. Quantitative imaging in late TBI. Part II: cognition and work after closed and penetrating head injury: a report of the Vietnam head injury study. Brain Inj. 2002;16(8):681-90.

[PMID:12167193]

http://dx.doi.org/10.1080/02699050110119835

7. Panczykowski DM, Puccio AM, Scruggs BJ, Bauer JS, Hricik AJ, Beers SR, Okonkwo DO. Prospective independent validation of IMPACT modeling as a prognostic tool in severe traumatic brain injury. J Neurotrauma. 2012;29(1): 47-52. [PMID:21933014] http://dx.doi.org/10.1089/neu.2010.1482

8. Roozenbeek B, Lingsma HF, Lecky FE, Lu J, Weir J, Butcher I, McHugh GS, Murray GD, Perel P, Maas AI, Steyerberg EW; International Mission on Prognosis Analysis of Clinical Trials in Traumatic Brain Injury (IMPACT) Study Group; Corticosteroid Randomisation After Significant Head Injury (CRASH) Trial Collaborators; Trauma Audit and Research Network (TARN). Prediction of outcome after moderate and severe traumatic brain injury: External validation of the International Mission on Prognosis and Analysis of Clinical Trials (IMPACT) and Corticoid Randomisation After Significant Head injury (CRASH) prognostic models. Crit Care Med. 2012;40(5):1609-17. [PMID:22511138] http://dx.doi.org/10.1097/CCM.0b013e31824519ce

9. Nichol AD, Higgins AM, Gabbe BJ, Murray LJ, Cooper DJ, Cameron PA. Measuring functional and quality of life outcomes following major head injury: Common scales and checklists. Injury. 2011;42(3):281-87.

[PMID:21145059] http://dx.doi.org/10.1016/j.injury.2010.11.047

10. Hanks RA, Millis SR, Ricker JH, Giacino JT, NakeseRichardson R, Frol AB, Novack TA, Kalmar K, Sherer M, Gordon WA. The predictive validity of a brief inpatient neuropsychologic battery for persons with traumatic brain injury. Arch Phys Med Rehabil. 2008;89(5):950-57. [PMID:18452745] http://dx.doi.org/10.1016/j.apmr.2008.01.011

11. Shukla D, Devi BI, Agrawal A. Outcome measures for traumatic brain injury. Clin Neurol Neurosurg. 2011;113(6):
435-41. [PMID:21440363]

http://dx.doi.org/10.1016/j.clineuro.2011.02.013

12. Laxe S, Tschiesner U, Zasler N, López-Blazquez R, Tormos JM, Bernabeu M. What domains of the International Classification of Functioning, Disability and Health are covered by the most commonly used measurement instruments in traumatic brain injury research? Clin Neurol Neurosurg. 2012;114(6):645-50. [PMID:22245447] http://dx.doi.org/10.1016/j.clineuro.2011.12.038

13. Bagiella E, Novack TA, Ansel B, Diaz-Arrastia R, Dikmen $\mathrm{S}$, Hart T, Temkin N. Measuring outcome in traumatic brain injury treatment trials: Recommendations from the traumatic brain injury clinical trials network. J Head Trauma Rehabil. 2010;25(5):375-82. [PMID:20216459]

14. Nakase-Richardson R, Whyte J, Giacino JT, Pavawalla S, Barnett SD, Yablon SA, Sherer M, Kalmar K, Hammond FM, Greenwald B, Horn LJ, Seel R, McCarthy M, Tran J, Walker WC. Longitudinal outcome of patients with disordered consciousness in the NIDRR TBI Model Systems Programs. J Neurotrauma. 2012;29(1):59-65.

[PMID:21663544]

http://dx.doi.org/10.1089/neu.2011.1829

15. Sandhaug M, Andelic N, Vatne A, Seiler S, Mygland A. Functional level during sub-acute rehabilitation after traumatic brain injury: Course and predictors of outcome. Brain Inj. 2010;24(5):740-47. [PMID:20334472] http://dx.doi.org/10.3109/02699051003652849

16. Keyser-Marcus LA, Bricout JC, Wehman P, Campbell LR, Cifu DX, Englander J, High W, Zafonte RD. Acute predictors of return to employment after traumatic brain injury: A longitudinal follow-up. Arch Phys Med Rehabil. 2002; 83(5):635-41. [PMID:11994802] http://dx.doi.org/10.1053/apmr.2002.31605

17. Chua K, Chuo A, Kong KH. Urinary incontinence after traumatic brain injury: Incidence, outcomes and correlates. Brain Inj. 2003;17(6):469-78. [PMID:12745703] http://dx.doi.org/10.1080/02699050210154268

18. Masel BE, DeWitt DS. Traumatic brain injury: A disease process, not an event. J Neurotrauma. 2010;27(8):1529-40. [PMID:20504161] http://dx.doi.org/10.1089/neu.2010.1358

19. Sherer M, Struchen MA, Yablon SA, Wang Y, Nick TG. Comparison of indices of traumatic brain injury severity: Glasgow Coma Scale, length of coma and post-traumatic amnesia. J Neurol Neurosurg Psychiatry. 2008;79(6):678-85. [PMID:17928328] http://dx.doi.org/10.1136/jnnp.2006.111187

20. The Brain Trauma Foundation. The American Association of Neurological Surgeons. The Joint Section on Neurotrauma and Critical Care. Glasgow coma scale score. J Neurotrauma. 2000;17(6-7):563-71. [PMID:10937902] 
21. Zafonte RD, Hammond FM, Mann NR, Wood DL, Black KL, Millis SR. Relationship between Glasgow coma scale and functional outcome. Am J Phys Med Rehabil. 1996;75(5): 364-69. [PMID:8873704] http://dx.doi.org/10.1097/00002060-199609000-00012

22. Choi JH, Jacob M, Stapf C, Marshall RS, Hartmann A, Mast H. Multimodal early rehabilitation and predictors of outcome in survivors of severe TBI. J Trauma Inj Infect Crit Care. 2008;65(5):1028-35. http://dx.doi.org/10.1097/TA.0b013e31815eba9b

23. Dikmen SS, Corrigan JD, Levin HS, Machamer J, Stiers W, Weisskopf MG. Cognitive outcome following traumatic brain injury. J Head Trauma Rehabil. 2009;24(6):430-38. [PMID:19940676] http://dx.doi.org/10.1097/HTR.0b013e3181c133e9

24. Nakase-Richardson R, Sepehri A, Sherer M, Yablon SA, Evans C, Mani T. Classification schema of posttraumatic amnesia duration-based injury severity relative to 1 -year outcome: Analysis of individuals with moderate and severe traumatic brain injury. Arch Phys Med Rehabil. 2009;90(1): 17-19. [PMID:19154824]

http://dx.doi.org/10.1016/j.apmr.2008.06.030

25. Kosch Y, Browne S, King C, Fitzgerald J, Cameron I. Posttraumatic amnesia and its relationship to the functional outcome of people with severe traumatic brain injury. Brain Inj. 2010;24(3):479-85. [PMID:20184405] http://dx.doi.org/10.3109/02699051003610417

26. Levin HS, O'Donnell VM, Grossman RG. The Galveston Orientation and Amnesia Test. A practical scale to assess cognition after head injury. J Nerv Ment Dis. 1979;167(11): 675-84. [PMID:501342] http://dx.doi.org/10.1097/00005053-197911000-00004

27. Walker WC, McDonald SD. Does neurologic examination during inpatient rehabilitation help predict global outcome after nonpenetrating traumatic brain injury? PM R. 2011; 3(1):6-12. [PMID:21257127] http://dx.doi.org/10.1016/j.pmrj.2010.11.001

28. Dikmen S, Machamer J, Powell J, Temkin N. Dikmen SS, Machamer JE, Powell JM, Temkin NR. Outcome 3 to 5 years after moderate to severe traumatic brain injury. Arch Phys Med Rehabil. 2003;84(10):1449-57.

[PMID:14586911]

http://dx.doi.org/10.1016/S0003-9993(03)00287-9

29. King JT Jr, Carlier PM, Marion DW. Early Glasgow Outcome Scale scores predict long-term functional outcome in patients with severe traumatic brain injury. J Neurotrauma. 2005;22(9):947-54. [PMID:16156710] http://dx.doi.org/10.1089/neu.2005.22.947

30. Shames J, Treger I, Ring H, Giaquinto S. Return to work following traumatic brain injury: Trends and challenges. Disabil Rehabil. 2007;29(17):1387-95. [PMID:17729084] http://dx.doi.org/10.1080/09638280701315011
31. Grauwmeijer E, Heijenbrok-Kal MH, Haitsma IK, Ribbers GM. A prospective study on employment outcome 3 years after moderate to severe traumatic brain injury. Arch Phys Med Rehabil. 2012;93(6):993-99. [PMID:22502806] http://dx.doi.org/10.1016/j.apmr.2012.01.018

32. Nimgade A, Costello MC. Return to work for a company president with traumatic brain injury. J Head Trauma Rehabil. 2003;18(5):464-67. [PMID:12973276] http://dx.doi.org/10.1097/00001199-200309000-00008

33. Walker WC, Marwitz JH, Kreutzer JS, Hart T, Novack TA. Occupational categories and return to work after traumatic brain injury: A multicenter study. Arch Phys Med Rehabil. 2006;87(12):1576-82. [PMID:17141636] http://dx.doi.org/10.1016/j.apmr.2006.08.335

34. Leitgeb J, Mauritz W, Brazinova A, Janciak I, Majdan M, Wilbacher I, Rusnak M. Effects of gender on outcomes after traumatic brain injury. J Trauma. 2011;71(6):1620-26. [PMID:21808209] http://dx.doi.org/10.1097/TA.0b013e318226ea0e

35. Kostić A, Stefanović I, Novak V, Veselinović D, Ivanov G, Veselinović A. Prognostic significance of intracranial pressure monitoring and intracranial hypertension in severe brain trauma patients. Med Pregl. 2011;64(9-10):461-65. [PMID:22097111] http://dx.doi.org/10.2298/MPNS1110461K

36. Ahmadi SA, Meier U, Lemcke J. Detailed long-term outcome analysis after decompressive craniectomy for severe traumatic brain injury. Brain Inj. 2010;24(13-14):1539-49. [PMID:20973624] http://dx.doi.org/10.3109/02699052.2010.523049

37. Brown JB, Stassen NA, Cheng JD, Sangosanya AT, Bankey PE, Gestring ML. Trauma center designation correlates with functional independence after severe but not moderate traumatic brain injury. J Trauma. 2010;69(2):263-69. [PMID:20699734] http://dx.doi.org/10.1097/TA.0b013e3181e5d72e

38. Eastvold AD, Walker WC, Curtiss G, Schwab K, Vanderploeg RD. The differential contributions of posttraumatic amnesia duration and time since injury in prediction of functional outcomes following moderate-to-severe traumatic brain injury. J Head Trauma Rehabil. 2013;28(1):48-58. [PMID:22333678] http://dx.doi.org/10.1097/HTR.0b013e31823c9317

39. Andelic N, Bautz-Holter E, Ronning P, Olafsen K, Sigurdardottir S, Schanke AK, Sveen U, Tornas S, Sandhaug $\mathrm{M}$, Roe C. Does an early onset and continuous chain of rehabilitation improve the long-term functional outcome of patients with severe traumatic brain injury? J Neurotrauma. 2012;29(1):66-74. [PMID:21864138] http://dx.doi.org/10.1089/neu.2011.1811

40. Kramer ME, Suskauer SJ, Christensen JR, DeMatt EJ, Trovato MK, Salorio CF, Slomine BS. Examining acute 
rehabilitation outcomes for children with total functional dependence after traumatic brain injury: A pilot study. J Head Trauma Rehabil. 2013;28(5):361-70. [PMID:22613944] http://dx.doi.org/10.1097/HTR.0b013e31824da031

41. Tepas JJ 3rd, Leaphart CL, Pieper P, Beaulieu CL, Spierre LR, Tuten JD, Celso BG. The effect of delay in rehabilitation on outcome of severe traumatic brain injury. J Pediatr Surg. 2009;44(2):368-72. [PMID:19231536] http://dx.doi.org/10.1016/j.jpedsurg.2008.10.089

42. Tsakanikas D, Relkin N. Normal pressure hydrocephalus. Semin Neurol. 2007;27(1):58-65. [PMID:17226742] http://dx.doi.org/10.1055/s-2006-956756

43. Kolakowsky-Hayner SA, Hammond FM, Wright J, Novack TA, Englander J, Diaz-Arrastia R, Dennison A, Sueno P. Ageing and traumatic brain injury: Age, decline in function and level of assistance over the first 10 years post-injury. Brain Inj. 2012;26(11):1328-37. [PMID:22897421] http://dx.doi.org/10.3109/02699052.2012.706353

44. Morris A, Browne G, Saltmarche A. Urinary incontinence: Correlates among cognitively impaired elderly veterans. J Gerontol Nurs. 1992;18(10):33-40. [PMID:1479156]

45. Myint PK, Vowler SL, Redmayne O, Fulcher RA. Cognition, continence and transfer status at the time of discharge from an acute hospital setting and their associations with an unfavourable discharge outcome after stroke. Gerontology. 2008;54(4):202-9. [PMID:18408357]

http://dx.doi.org/10.1159/000126491

46. Akiguchi I, Ishii M, Watanabe Y, Watanabe T, Kawasaki T, Yagi H, Shiino A, Shirakashi Y, Kawamoto Y. Shuntresponsive parkinsonism and reversible white matter lesions in patients with idiopathic NPH. J Neurol. 2008; 255(9):1392-99. [PMID:18575921] http://dx.doi.org/10.1007/s00415-008-0928-1

47. Zhang H, Reitz A, Kollias S, Summers P, Curt A, Schurch B. An fMRI study of the role of suprapontine brain structures in the voluntary voiding control induced by pelvic floor contraction. Neuroimage. 2005;24(1):174-80. [PMID:15588608] http://dx.doi.org/10.1016/j.neuroimage.2004.08.027

48. DuBose JJ, Barmparas G, Inaba K, Stein DM, Scalea T, Cancio LC, Cole J, Eastridge B, Blackbourne L. Isolated severe traumatic brain injuries sustained during combat operations: Demographics, mortality outcomes, and lessons to be learned from contrasts to civilian counterparts. J Trauma. 2011;70(1):11-16, discussion 16-18. [PMID:21217475] http://dx.doi.org/10.1097/TA.0b013e318207c563

49. Majdan M, Mauritz W, Brazinova A, Rusnak M, Leitgeb J, Janciak I, Wilbacher I. Severity and outcome of traumatic brain injuries (TBI) with different causes of injury. Brain Inj. 2011;25(9):797-805. [PMID:21631184] http://dx.doi.org/10.3109/02699052.2011.581642
50. Bushnik T, Hanks RA, Kreutzer J, Rosenthal M. Etiology of traumatic brain injury: Characterization of differential outcomes up to 1 year postinjury. Arch Phys Med Rehabil. 2003;84(2):255-62. [PMID:12601658] http://dx.doi.org/10.1053/apmr.2003.50092

51. Ling G, Bandak F, Armonda R, Grant G, Ecklund J. Explosive blast neurotrauma. J Neurotrauma. 2009;26(6):815-25. [PMID:19397423] http://dx.doi.org/10.1089/neu.2007.0484

52. Yurgil KA, Barkauskas DA, Vasterling JJ, Nievergelt CM, Larson GE, Schork NJ, Litz BT, Nash WP, Baker DG; Marine Resiliency Study Team. Association between traumatic brain injury and risk of posttraumatic stress disorder in active-duty Marines. JAMA Psychiatry. 2014;71(2): 149-57. [PMID:24337530] http://dx.doi.org/10.1001/jamapsychiatry.2013.3080

53. Masel BE, Bell RS, Brossart S, Grill RJ, Hayes RL, Levin HS, Rasband MN, Ritzel DV, Wade CE, DeWitt DS. Galveston Brain Injury Conference 2010: Clinical and experimental aspects of blast injury. J Neurotrauma. 2012; 29(12):2143-71. [PMID:22655746]

http://dx.doi.org/10.1089/neu.2011.2258

54. Nampiaparampil DE. Prevalence of chronic pain after traumatic brain injury: A systematic review. JAMA. 2008; 300(6):711-19. [PMID:18698069] http://dx.doi.org/10.1001/jama.300.6.711

55. Kushner D. Mild traumatic brain injury: Toward understanding manifestations and treatment. Arch Intern Med. 1998;158(15):1617-24. [PMID:9701095] http://dx.doi.org/10.1001/archinte.158.15.1617

56. Maller JJ, Thomson RH, Pannek K, Rose SE, Bailey N, Lewis PM, Fitzgerald PB. The (Eigen)value of diffusion tensor imaging to investigate depression after traumatic brain injury. Hum Brain Mapp. 2014;35(1):227-37. [PMID:23008175] http://dx.doi.org/10.1002/hbm.22171

57. Starkstein SE, Tranel D. Neurological and psychiatric aspects of emotion. Handb Clin Neurol. 2012;106:53-74. [PMID:22608615] http://dx.doi.org/10.1016/B978-0-444-52002-9.00004-8

58. Depue BE, Olson-Madden JH, Smolker HR, Rajamani M, Brenner LA, Banich MT. Reduced amygdala volume is associated with deficits in inhibitory control: A voxel- and surface-based morphometric analysis of comorbid PTSD/ mild TBI. Biomed Res Int. 2014;2014:691505. [PMID:24724093] http://dx.doi.org/10.1155/2014/691505

59. Patel R, Spreng RN, Shin LM, Girard TA. Neurocircuitry models of posttraumatic stress disorder and beyond: A meta-analysis of functional neuroimaging studies. Neurosci Biobehav Rev. 2012;36(9):2130-42. [PMID:22766141] http://dx.doi.org/10.1016/j.neubiorev.2012.06.003 
JRRD, Volume 51, Number 7, 2014

60. Karl A, Schaefer M, Malta LS, Dörfel D, Rohleder N, Werner A. A meta-analysis of structural brain abnormalities in PTSD. Neurosci Biobehav Rev. 2006;30(7):1004-31. [PMID:16730374] http://dx.doi.org/10.1016/j.neubiorev.2006.03.004

Submitted for publication January 7, 2014. Accepted in revised form May 6, 2014
This article and any supplementary material should be cited as follows:

Kushner DS, Johnson-Greene D. Changes in cognition and continence as predictors of rehabilitation outcomes in individuals with severe traumatic brain injury. J Rehabil Res Dev. 2014;51(7):1057-68. http://dx.doi.org/10.1682/JRRD.2014.01.0002 